\title{
Percepção do estresse ocupacional de bibliotecários que atuam na Universidade Estadual do Piauí (Uespi)
}

\author{
Perception of occupational stress of librarians who work at the \\ Universidade Estadual do Piauí (Uespi)
}

\section{Percepción del estrés laboral de bibliotecarios que trabajan en la Universidade Estadual do Piauí (Uespi)}

\author{
Lucas Veras de Andrade | lukkandrade18@hotmail.com \\ Secretaria Municipal de Educação de Teresina (SEMEC), Teresina, Piauí, Brasil. \\ JoimaraLima Santos|joimara@gmail.com \\ Universidade Federal do Piaú́ (UFPI), Teresina, Piauí, Brasil.
}

\section{Resumo}

Este artigo aborda uma pesquisa que se debruça sobre a temática do estresse ocupacional, colocando-o em pauta na atividade bibliotecária da Universidade Estadual do Piauí (Uespi). Apresenta um breve histórico do surgimento do estresse e sua conceituação de maneira geral e, especificamente, a do ocupacional. Nosso estudo tem caráter qualitativo, contemplando levantamento bibliográfico e pesquisa de campo. A coleta de dados se deu juntamente a cinco bibliotecários, cujas atribuições estão sendo desenvolvidas em três campi da Uespi, no município de Teresina (PI), tendo sido aplicado um questionário com questões abertas, que foi analisado em seguida a partir da técnica de análise de conteúdo. É demonstrado pela maioria de nossos interlocutores que a profissão não é percebida como estressante. É evidenciado ainda que, no caso dos profissionais bibliotecários analisados, os estressores estão envoltos por dois aspectos: o primeiro se refere ao fato de conciliar as atividades exigidas pelo cotidiano do trabalho, e o segundo diz respeito ao nível de satisfação dos indivíduos.

Palavras-chave: Percepção; Estresse fisiológico; Estresse psicológico; Bibliotecários; Serviços de Biblioteca; Doenças profissionais. Exposição ocupacional. Esgotamento profissional. Trabalhadores. Saúde do trabalhador. Questionários. Pesquisa qualitativa.

\footnotetext{
Abstract

This article deals with a research focused on the theme of occupational stress, approaching the librarian activity at the Universidade Estadual do Piauí - Uespi (Piauí State University). It presents a brief history of the emergence of stress and its concept and particularly the conceptualization of occupational stress. Our study has qualitative character contemplating literature review and field research. Data collection took place interviewing five librarians whose duties are being developed in three campuses of Uespi, in the city of Teresina (PI). The five librarians were asked to answer open questions which we later have analyzed from technical analysis content. It is demonstrated by the most of respondents that the profession is not
} 
perceived as stressful. It is also evidenced that the stressors for professional librarians are closely associated with two aspects: the first refers to reconcile the activities required for daily work and the second concerns the level of satisfaction of individuals.

Keywords: Perception. Physiological stress. Psychological stress. Librarians. Library services. Occupational diseases. Occupational exposure. Professional exhaustion. Workers. Worker's health. Interviews. Qualitative research.

\section{Resumen}

Este artículo presenta una investigación centrada en el tema del estrés laboral, abordando el tema en la actividad bibliotecaria de la Universidade Estadual do Piauí - Uespi (Universidad del Estado de Piauí). Él hace un breve histórico del surgimiento de estrés y su concepto en general y presenta de una manera específica la conceptualización de estrés laboral. Nuestro estudio tiene naturaleza cualitativa, incluyendo revisión de la literatura y investigación de campo. La recolección de datos ha sido realizada entrevistando cinco bibliotecarios cuyas funciones se están desarrollando en tres campus de la Uespi en la ciudad de Teresina (PI), mediante preguntas abiertas y las respuestas fueron analizadas después utilizando la técnica de análisis de contenido. El análisis ha demostrado que la mayoría de nuestros interlocutores no perciben la profesión como estresante. También es evidente que en el caso de los bibliotecarios analizados los estresores están encubiertos por dos aspectos: el primero se refiere a conciliar las actividades requeridas por el trabajo diario y el segundo se refiere al nivel de satisfacción de las personas.

Palabras clave: Percepción. Estrés fisiológico. Estrés psicológico. Bibliotecarios. Servicios de biblioteca. Enfermedades laborales. Exposición ocupacional. Agotamiento profesional. Trabajadores. La salud del trabajador. Entrevistas. Investigación cualitativa.

\footnotetext{
Contribuição dos autores

Lucas Veras de Andrade: Contribuiu com a concepção e o desenho do estudo; Coleta, análise e interpretação dos dados; Redação do manuscrito; Análise estatística.

Joimara Lima Santos: Contribuiu com a revisão crítica do conteúdo intelectual; no planejamento do estudo, método e revisão das versões preliminares e definitiva do artigo, bem como aprovou a versão final.
}

Declaração de conflito de interesses: Declaram ainda não haver conflitos de interesse.

Fontes de financiamento: Não houve.

Considerações éticas: Pesquisa desenvolvida com o consentimento livre e esclarecido dos respondentes, mediante termo de confidencialidade assinado pelos mesmos.

Histórico do artigo: Submetido: 14.jan.2015 | Aceito: 6.fev.2015 | Publicado: 31.mar.2015

Licença: CC BY-NC atribuição não comercial. Com essa licença é permitido acessar, baixar (download), copiar, imprimir, compartilhar, reutilizar e distribuir os artigos, desde que para uso não comercial e com a citação da fonte, conferindo os devidos créditos de autoria. Nesses casos, nenhuma permissão é necessária por parte dos autores ou dos editores. 


\section{Introdução}

Estresse é um estado psíquico que conduz o indivíduo a uma situação de esgotamento que tende a desenvolver estados patogênicos ${ }^{1}$. O estresse, desde os primórdios da humanidade, sempre esteve presente na vida e nas relações estabelecidas pelos seres humanos. Isso fez com que os indivíduos passassem constantemente por situações de transformações e adaptações principalmente no que concerne ao equilíbrio emocional.

Ele passou a ser discutido com mais ponderação, a partir das condições materiais a que os indivíduos se submetem, na contemporaneidade ${ }^{2}$. Existe um consenso entre alguns autores, ao afirmarem que ele se configura como um dos vilões da vida moderna e é considerado, atualmente, como mal do século ${ }^{3,4}$. É fácil entender o porquê dos motivos dessa epidemia. Diariamente a sociedade se torna mais complexa e competitiva e o indivíduo, sem perceber, entra nas cobranças e na busca de um objetivo, deixando seu bem-estar em segundo plano, submetendo-se às pressões do trabalho, das relações pessoais, adquirindo assim, hábitos prejudiciais à qualidade de vida.

Desse modo, "o estresse no trabalho é defendido como reações físicas e emocionais que ocorrem quando as exigências excedem às capacidades, aos recursos ou às necessidades do trabalhador”. Essas reações podem ser desencadeadas por várias vertentes: pela necessidade de atualização profissional constante, assim como pode ser desenvolvida pela competitividade, entre outros aspectos resultantes das constantes transformações que ocorrem na sociedade e deixam o ser humano em constante desequilíbrio.

Nesta perspectiva, levando esses aspectos para o ambiente de órgãos públicos de trabalho, nosso lócus de pesquisa, acrescentamos ainda a pouca autonomia em participações de decisões, a ausência de reconhecimento profissional, atribuições repetitivas e pouco significativas como também o mau relacionamento com chefes e demais colegas. Situações como estas, quando vivenciadas no ambiente de trabalho podem desencadear mal-estar, frustração, insatisfação no trabalhador, permitindo, assim, o desencadeamento do estresse ocupacional.

O estresse ocupacional é conceituado por vários autores. Segundo Cherniss ${ }^{{ }^{i *}}$, é causado por características do ambiente de trabalho ${ }^{6}$. Para Karasek ${ }^{\mathrm{ii}^{*}}$, o estresse ocupacional é visto como as respostas emocionais e físicas ocorridas quando as exigências do trabalho não estão em equilíbrio com as necessidades do trabalhador?

Entendemos estresse ocupacional como uma perturbação de caráter psicológico em que a compreensão pode ser feita a partir de várias vertentes, não sendo suas geradoras nem a situação, nem a resposta, e sim a concepção que o indivíduo tem sobre a situação. Com relação ao estresse, podemos mencionar ainda a síndrome de burnout, que pode ser entendida como uma cronificação do estresse ocupacional e que é caracterizada a partir de três dimensões: exaustão emocional, despersonalização e baixa realização profissional.

Dessa forma, analisar aspectos que podem reduzir a produtividade do funcionário dentro de uma empresa e/ou órgão público torna-se relevante na medida em que se observa a problemática sob o viés econômico. Nossa afirmativa embasa-se quando observamos discursos como "A preocupação das organizações com as necessidades de saúde de seus empregados é garantia de rendimento para a empresa e sociedade, sendo impossível ignorar tal fato quando se busca desempenho eficaz" ${ }^{\text {. }} \mathrm{O}$ autor ressalta a necessidade de atentarmos para a saúde do trabalhador, uma vez que esta é fator de interferência na produtividade e, quando comprometida, pode causar doenças e, em casos extremos, levar a óbito.

Ao observarmos a saúde do trabalhador, colocamos em pauta o estresse ocupacional que pode ser desenvolvido no cotidiano da atividade profissional de bibliotecário. No estudo, evidenciaremos a prática 
dos profissionais bibliotecários dos campi Poeta Torquato Neto, Faculdade de Ciências Médicas (Facime) e Clóvis Moura da Universidade Estadual do Piauí (Uespi) e como eles próprios analisam suas práticas profissionais, condições de trabalho e os aspectos mencionados pelos autores como desencadeadores de estresse ocupacional, com o intuito de verificá-lo na categoria profissional em discussão.

Diante do exposto e tendo como ponto de partida a opinião dos teóricos citados anteriormente em relação ao estresse, estresse ocupacional e suas implicações sobre a saúde do trabalhador, faz-se a seguinte indagação a respeito do assunto: no contexto atual da atividade bibliotecária na Universidade Estadual do Piauí existe estresse ocupacional?

Portanto, propõe-se, como objetivo geral deste estudo, investigar se os bibliotecários da Universidade Estadual do Piauí apresentam sintomas de estresse ocupacional.

Para a realização deste propósito colocam-se as seguintes etapas:

1. Evidenciar se a atividade exercida pelo bibliotecário é percebida como estressante;

2. Verificar a existência de elementos estressores no exercício das atividades ocupacionais desse profissional no contexto laboral da Universidade Estadual do Piauí;

3. Caso os profissionais em questão apresentem sintomas de estresse ocupacional, buscar evidenciar que implicações esses elementos trazem para eles bem como para a instituição em pauta.

Na busca de solucionar o problema de pesquisa evidenciado e de alcançar os objetivos propostos, estruturamos nossa investigação em seções, sendo a primeira a introdução. Nela, apresentamos os objetivos que pretendemos alcançar com a pesquisa.

Na segunda, explanamos sobre o método, descrevendo o tipo de pesquisa realizada, o contexto e sujeitos do estudo, os instrumentos adotados e, por fim, apontamos os procedimentos utilizados para a análise dos dados.

$\mathrm{Na}$ terceira, temos um breve histórico do surgimento do estresse e sua conceituação, bem como a concepção que admitimos, tomando por aspectos essenciais os estudos de Seyle ${ }^{8}$. Apresentamos ainda, na mesma seção, a conceituação de estresse ocupacional, demonstrando a sua relação com a saúde do trabalhador bem como as suas consequências para as organizações.

Na quarta seção, efetivam-se as análises realizadas e que foram organizadas a partir de três categorias.

Posteriormente, temos as considerações finais em que se retomam os principais achados da pesquisa.

Procedimentos metodológicos

O estudo, aqui apresentado, foi realizado em três bibliotecas universitárias vinculadas à Universidade Estadual do Piauí, na cidade de Teresina (PI), a partir de uma pesquisa qualitativa, por meio da aplicação de questionários iguais a todos os participantes.

Foram entrevistados cinco bibliotecários de faixa etária entre 25 a 39 anos que atuam na referida universidade, sendo quatro do sexo feminino e um do sexo masculino. Os critérios para a escolha de nossos respondentes foram, a princípio, os de estarem desenvolvendo atividades de bibliotecários na universidade em questão, terem formação em biblioteconomia e participarem voluntariamente da pesquisa.

Como já mencionamos, o instrumento utilizado para coletar os dados foi um questionário com questões abertas, por entendermos que ele traduz os objetivos da pesquisa em perguntas claras e objetivas e por permitir, aos respondentes, espaço para demonstrarem suas opiniões. Constituído por cinco questões, teve o intuito de discutir como os profissionais analisados percebem o estresse ocupacional no espaço laboral da universidade analisada.

O conteúdo dos questionários foi analisado a partir da técnica de análise de conteúdo. Assim, o discurso evidenciado por nossos analisados nos permitiu iniciar o que Bardin ${ }^{9}$ denomina leitura minuciosa. A 
estruturação desses discursos, a partir dos registros escritos, deu origem às categorias de análise, o que nos permitiu demonstrar os elementos mais recorrentes no conteúdo dos discursos e organizá-los, por ordem de proximidade, em categorias e subcategorias.

Assim, recorrendo às orientações da análise de conteúdo e tendo por base o referencial teórico adotado, construímos três categorias, cada uma composta por subcategorias. Então, à luz de Bardin ${ }^{9}$, organizamos os dados, fizemos a descrição, inferências e, por fim, o diálogo interpretativo dos discursos coletados. Toda essa trajetória foi desenvolvida levando em consideração os objetivos de nossa pesquisa, juntamente com a discussão de outras pesquisas e o referencial teórico adotado.

\section{Compreendendo o estresse e as suas manifestações: reflexões teóricas}

O estresse não é uma temática atual, entretanto, é um fenômeno que cada vez mais chama atenção dos estudiosos, pois se configura como um risco para a homeostase (equilíbrio do organismo) do ser humano. O estresse é uma característica típica dos tempos modernos, da vida cheia de tensões, do mundo agitado que supera um simples cansaço físico e mental ${ }^{10}$. É causado pela ação de defesas orgânicas decorrente de estímulos físicos, psicológicos ou psicossociais. Constitui uma adaptação do organismo e produz uma sucessão de transformações físicas e químicas acionadas pelo sistema nervoso. O estresse pode provocar desde uma simples dor de cabeça até um enfarte.

Seyle caracterizou estresse como uma síndrome denominada Síndrome Geral da Adaptação (SAG), que possui três fases: alarme, resistência e exaustão ${ }^{8}$. A fase de alarme é evidenciada por forças de defesas; na segunda, chamada de resistência, o estressor continua agindo sobre o indivíduo causando tensão e, por fim, a exaustão, fase esta muito semelhante à reação de alarme, por apresentar falhas no meio de adaptação mas que, por motivo de esgotamento, pode levar à morte.

$\mathrm{O}$ autor $^{8}$ afirma, ainda, que o conceito de estresse inicialmente era usado para descrever fenômenos físicos, como calor ou força aplicada, algo extrínseco ao ser humano. O estresse foi considerado epidemia nos anos 1980 e, com a evolução do saber científico, o conceito passou a ser trabalhado com estatuto de ciência.

Walter B. Cannon ${ }^{\text {iii* }}$, fisiologista de Harvard, foi o primeiro a estudá-lo e, em seus estudos, já percebia uma interligação do sistema nervoso, endócrino, aproximando o conceito de estresse do que ele é hoje. Ao longo do tempo, Cannon concluiu em seus estudos que o estresse é também desencadeado por reações orgânicas.

O estresse pode ser entendido como uma reação e/ou adaptação do organismo a estímulos físicos e/ ou psicológicos que afetam o ser humano tanto de forma negativa (distress), quanto positiva (eustress), e o seu entendimento pode ser compreendido através de várias vertentes (emocional, ambiental, biológica e física), não sendo nem a situação nem a resposta o definidor do estresse, mas a percepção do indivíduo sobre a situaçãa $\mathrm{iv}^{\mathrm{iv}}$.

Para Sparrenberger, Santos e Lima ${ }^{12}$, o estresse é ${ }^{12}$ :

Conceitualmente entendido como um processo complexo e multidimensional, em que atuam estressores agudos ou crônicos dos seguintes tipos: ambientais (no trabalho, em casa ou na vizinhança, por exemplo), eventos maiores (como mudança de domicílio, morte ou doença em familiar, separação conjugal e desemprego), trauma (por exemplo, participar de um combate, ser vítima ou presenciar crime violento ou acidente de trânsito e estar envolvido em desastres naturais ou industriais) e abuso ou negligência na infância e na velhice. Tais estressores são percebidos pelo indivíduo como ameaça, necessidade de ajuda ou alerta, o que dá início a uma resposta, visando a adaptar-se à situação.

iii *1932, apud Childre ${ }^{10}$

iv "Monat, 1977, apud Stacciarini; Tróccoli ${ }^{11}$ 
A adaptação, nesse sentido, pode ser entendida como um processo contínuo de ajuste a que o indivíduo está sujeito. Segundo Clark ${ }^{v^{*}}$, existem três formas de definição do estresse: como resposta, estímulo e, por fim, interação ou transação.

Segundo Bicho e Pereira, o estresse como resposta é originário da medicina, focado na perspectiva fisiológica. A reação do organismo pode se evidenciar de três formas: a) reação de alarme, sendo ela caracterizada como resposta aos estímulos para os quais o organismo não está preparado, b) estado de resistência que se apresenta como a substituição da reação de alarme, em que o organismo se adapta, ou seja, o organismo se reestrutura ao agente estressor e c) estado de exaustão, quando as fases anteriores citadas ocorrem de forma intensa ou perduram por um longo período ${ }^{13}$.

No que se refere ao estresse como estímulo, sua conceituação é advinda da física e é definido como uma força aplicada sobre o indivíduo. Essa força resulta numa reação do organismo que tolera até certo nível e pode provocar danos temporários ou permanentes ${ }^{13}$.

Existe uma divergência, entre autores, sobre a conceituação do estresse na perspectiva da interação ou transação, que discutem essa perspectiva por um viés dissociado. Entretanto, neste estudo, adotamos a conceituação de estresse definida a partir da associação desses dois termos e, para isso, utilizamos os estudos de Bicho e Pereira ${ }^{13}$.

Segundo esses autores, o estresse na perspectiva da interação ou transação é definido numa abordagem integracionista, em que o indivíduo age e reage com o meio ambiente, ou seja, o estresse não está nem na pessoa nem no ambiente, mas na troca ou interação entre os dois.

Desse modo, focaremos a seguir o estresse associado ao trabalho, conceituado por vários autores como estresse ocupacional, e será apresentado o que vem a desencadeá-lo no indivíduo em seu espaço de trabalho.

\section{Estresse ocupacional}

Na visão de Lipp, as pessoas, em sua grande maioria, ocupam grande parte de seu tempo com o trabalho, devido à intensa carga horária que lhes é exigida e ao acúmulo de tarefas na atividade exercida ${ }^{2}$. Esses aspectos desencadeiam insatisfação e, por conseguinte, estresse ocupacional causando ameaças físicas, psíquicas e interferindo até mesmo no desempenho desse trabalhador. Nesse sentido, Fernandes, Medeiros

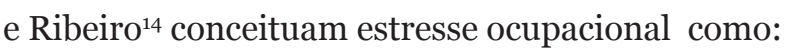

Consequência das relações complexas que se processam entre condições de trabalho, condições externas ao trabalho e características individuais do trabalhador, nas quais as demandas do trabalho excedem as habilidades do trabalhador para enfrentá-las.

Temos ainda o conceito de Campos ${ }^{15}$, que diz ser a ausência de energia causada por fadiga ou por forte pressão no trabalho. E o de Chiavenato ${ }^{16}$, que define e avalia o estresse da seguinte forma:

O estresse é uma decorrência de pressões e tensões que se acumulam e que pesam sobre o indivíduo e provocam sérias consequências sobre a saúde mental no trabalho. A palavra estresse tem sido utilizada para designar os sintomas produzidos pelo organismo humano em resposta à tensão provocada pelas pressões, situações e ações externas que as pessoas enfrentam no seu cotidiano. Como resultado dessas pressões ou situações, as pessoas desenvolvem vários sintomas - como preocupação, irritabilidade, agressividade, fadiga, ansiedade e angústia - que podem prejudicar seu desempenho no trabalho e sua saúde.

Chiavenato ${ }^{16}$ conceitua estresse ocupacional como uma manifestação que acarreta sofrimento psíquico e está relacionado às experiências do trabalho. De acordo com Guimarães ${ }^{\mathrm{vi}}$, o estresse ocupacional ocorre quando o trabalhador percebe sua incapacidade de realizar no seu espaço laboral, suas atividades profissionais, o que provoca sofrimento, mal-estar e sentimento de frustração.

\footnotetext{
v "1984, apud Stacciarini; Tróccoli11

vi ${ }^{*} 2000$, apud $^{13}$
} 
$\mathrm{Na}$ visão de Stacciarini e Tróccoli ${ }^{11}$, o estresse é um fenômeno de natureza perceptiva com caráter negativo, resultado da incapacidade do indivíduo lidar com as fontes geradoras de pressão no trabalho. Ainda temos a definição de Monat e Lazarus ${ }^{\text {vii* }}$, que afirmam que estresse ocupacional é uma condição de desequilíbrio real ou percebido entre as demandas do ambiente e os recursos adaptativos dos indivíduos.

Podemos perceber que existe um consenso quanto à definição de estresse ocupacional entre os autores que fundamentam esse estudo. Autores como Hilldebrandt ${ }^{\text {viii }}$ além de Smith, Kaminstein e Makadok ${ }^{18}$ argumentam ainda que existem relações significativas estáveis entre os fatores psicossociais do ambiente de trabalho e a saúde física do trabalhador. Desse modo, evidenciaremos a seguir uma breve discussão sobre os fatores psicossociais de estresse ocupacional e os efeitos do estresse sobre a saúde do trabalhador.

\section{Fatores psicossociais e as consequências do estresse ocupacional}

Segundo Pinheiro e Gunther, várias são as fontes de estresse ocupacional consideradas de ordem psicossocial, e podem-se incluir um ou mais dos seguintes fatores ${ }^{17}$ :

a) Relativos à tarefa: nesse fator incluem-se responsabilidades pelo trabalho de terceiros, os esforços físicos e mentais exigidos, a sobrecarga de trabalho, a preocupação pela qualidade do trabalho, a realização de horas extras por exigência do trabalho, o grau do desafio, os riscos à segurança pessoal, a clareza do trabalho e a adequação do conhecimento à atividade exercida;

b) Referentes ao papel ocupacional: referem-se ao conflito entre os papéis, ao grau de autonomia, à ambiguidade de papel, à importância atribuída ao trabalho e à autoestima ocupacional;

c) Referentes ao grupo ocupacional: neste âmbito, incluem-se o reconhecimento pela chefia, o grau de satisfação com a supervisão, o relacionamento com os colegas e com a chefia bem como a percepção de suporte social no grupo;

d) Referentes à organização: consideram-se as oportunidades de desenvolvimento, a imagem pública da empresa, o grau de identificação com os valores organizacionais e a percepção de equidade com o sistema de promoção.

Temos ainda a visão de Stacciarini e Tróccoli ${ }^{11}$, que afirmam que "os estressores no ambiente de trabalho podem ser categorizados em seis grupos: fatores intrínsecos para o trabalho, papéis estressores, relações no trabalho, estressores na carreira, estrutura organizacional e por fim interface casa-trabalho".

A primeira categoria diz respeito à existência ou ausência de condições no ambiente de trabalho como, por exemplo: turno de trabalho, carga de trabalho, pagamento, tecnologia utilizada no exercício da profissão. A segunda refere-se ao papel ambíguo ou conflituoso, o grau de responsabilidade para com as pessoas ou coisas.

A categoria relações no trabalho pode ser entendida como as más relações estabelecidas com o chefe, colegas e clientes, bem como todos que estejam direta ou indiretamente associados ao local de trabalho. $\mathrm{Na}$ categoria estressores na carreira, entendemos os aspectos que se relacionam ao desenvolvimento da profissão, bem como insegurança no trabalho.

A categoria estrutura organizacional é entendida como a ausência de um estilo de gerenciamento, bem como a falta de participação dos colaboradores da organização e ausência de comunicação entre eles. Por fim, temos a categoria interface casa-trabalho, que é perceptível quando o trabalhador sente dificuldade de manejá-la.

vii * 1985 , apud ${ }^{17}$

viii *1993, apud ${ }^{17}$ 
Podemos perceber que vários são os fatores que podem influenciar o desencadeamento do estresse ocupacional no indivíduo. Nesse contexto, podemos inferir que várias são as consequências do estresse. As mesmas podem recair tanto sobre o indivíduo no exercício da sua atividade profissional bem como na sua saúde, e principalmente sobre as organizações às quais estão vinculados.

As consequências diretas para o trabalhador são percebidas na sua saúde mental e física. Segundo Bicho e Pereira, uma vez que o estresse afeta o sistema nervoso, endócrino e imunológico, ele é causador de várias doenças ${ }^{13}$. Situação esta, que só é desenvolvida quando a situação estressora é muito prolongada, intensa ou frequente, ou quando o indivíduo não dispõe de recursos adequados de adaptação.

Percebe-se também, de acordo com Pinheiro e Gunther ${ }^{17}$, que o estresse pode agravar qualquer doença. Esses autores afirmam ainda, que outros efeitos importantes sobre a saúde física, desencadeados a partir do estresse, são alterações metabólicas que podem ser quantificáveis através de exames laboratoriais e do índice de massa corporal (IMC).

As consequências para as organizações são resultantes das individuais, ou seja, das que incidem diretamente no trabalhador. Dessa forma, ocorre uma elevação dos custos que tem origem em fatores como a minimização do rendimento dos trabalhadores, o aumento do absenteísmo e dos acidentes de trabalho.

\section{Análise e discussão dos resultados}

Apresentamos, nesta seção, os dados coletados a fim de analisar as respostas dos bibliotecários a partir do referencial teórico, buscando compreender as concepções dos mesmos sobre a temática pesquisada. A análise está organizada em três categorias denominadas: concepções de estresse ocupacional e a percepção dos bibliotecários sobre o mesmo na atividade desenvolvida; fatores geradores de estresse na atividade bibliotecária na Universidade Estadual do Piauí; e, por fim, as implicações dos estressores para a instituição Uespi e para os profissionais bibliotecários. Serão detalhadas a seguir.

\section{Concepções de estresse ocupacional e a percepção dos bibliotecários sobre o mesmo na atividade desenvolvida}

Para que pudéssemos compreender, a partir da perspectiva dos bibliotecários, se a atividade profissional desenvolvida por eles no espaço laboral das bibliotecas da Uespi era percebida como estressante, se fez necessário antes compreender o entendimento que os mesmos tinham sobre estresse. Desse modo, esta categoria foi dividida em dois momentos, como será descrito a seguir: o primeiro, em que se questionou qual a concepção de estresse dos bibliotecários e o segundo, investigando se a atividade bibliotecária desenvolvida por eles é percebida como estressante. Assim, mediante a transcrição dos questionários respondidos por eles, tivemos as seguintes respostas com relação ao primeiro momento:

Associo o estresse a um conjunto de reações e alterações no organismo que afetam o equilíbrio físico e emocional do indivíduo [...]. (bibliotecário 1).

É o cansaço físico e emocional proveniente de um trabalho exaustivo ou repetitivo. (bibliotecário 2).

Cansaço físico e/ou mental causado por excesso de atividades ou por fatores ambientais. (bibliotecário 3).

[...] cansaço físico e mental. (bibliotecário 4).

Situação em que indivíduo sente-se pressionado por algo ou alguém no ambiente de trabalho, isso pode ocasionar cansaço, fadiga. (bibliotecário 5). 
Para o bibliotecário 1, o estresse é conceituado como "um conjunto de reações e alterações no organismo que afetam o equilíbrio físico e emocional do indivíduo". Para os bibliotecários 2,3, 4 o estresse é visto como o cansaço físico, emocional e/ou mental. Entretanto, os bibliotecários 2 e 3 complementam seus conceitos afirmando que o estresse é "desencadeado a partir de um trabalho exaustivo ou repetitivo" (bibliotecário 2) e que é ocasionado a partir do "excesso de atividades ou por fatores ambientais" (bibliotecário 3).

A concepção de estresse, para o bibliotecário 5, está envolta "numa situação em que o indivíduo sente-se pressionado por algo ou alguém no ambiente de trabalho". Podemos inferir que é consenso entre todos os respondentes que o estresse ocupacional está associado a características fisiológicas e psicológicas como, por exemplo, o cansaço físico, emocional e/ou mental. Os bibliotecários 2, 3 e 5, ao mencionarem em seus conceitos breves características desencadeadoras de estresse ocupacional, afirmando que o mesmo é "desencadeado a partir de um trabalho exaustivo ou repetitivo" (bibliotecário 2), a partir do "excesso de atividades ou por fatores ambientais" (bibliotecário 3) e, por fim, "uma situação em que indivíduo sente-se pressionado por algo ou alguém no ambiente de trabalho" (bibliotecário 5), nos levam a inferir que essas características sejam aplicáveis nas atividades ocupacionais exercidas pelos profissionais em seu espaço de trabalho. Essas características convergem, de certa forma, para o conceito que admitimos e para os dos teóricos que discutem acerca da temática em questão e que foram escolhidos para dar suporte à análise dos dados.

Entretanto, as visões dos bibliotecários acima mencionados se caracterizam muito mais como fontes desencadeadoras de estresse do que os conceitos utilizados pelos teóricos. As características mencionadas pelos bibliotecários 2, 3 e 5 enquadram-se nos estudos de Pinheiro e Gunther ${ }^{17}$, principalmente no que eles denominaram fonte relativa ao trabalho que diz respeito às responsabilidades pelo trabalho de terceiros, ao esforço físico e mental exigidos, à sobrecarga de trabalho, à preocupação pela qualidade do trabalho, à realização de horas extras por exigência do trabalho, ao grau do desafio, aos riscos à segurança pessoal, à clareza do trabalho e, por fim, à adequação do conhecimento à atividade exercida.

Já a concepção de estresse do bibliotecário 1 gira em torno de "reações e alterações no organismo", o que o torna um conceito muito generalizado que não deve ser incorporado ao conceito de estresse ocupacional proposto no estudo. Entretanto, encontramos base para este conceito nos estudos de Bicho e Pereira ${ }^{13}$, em que o estresse é visto como uma resposta do organismo e é focado na perspectiva fisiológica.

Percebemos que a análise do conteúdo do questionamento que versa sobre a concepção de estresse dos bibliotecários, no geral, revela que todos nos remetem aos resultados do estresse e o associam a questões de ordem fisiológica. Entretanto, não definem o que seria estresse ocupacional como Lourenço e Almeida ${ }^{19}$ afirmam ser:

[...] uma reação negativa do organismo, a um estado crônico de estresse que o trabalhador pode estar vivenciando e que prejudica sua saúde física e mental e que podem ser classificados em várias categorias, sendo que alguns são predominantes de acordo com a área de atuação do trabalhador.

Segundo esses autores, o estresse ocupacional é visto como uma resposta do organismo ao estresse que o indivíduo pode estar vivenciando no seu espaço laboral, ou seja, o estresse ocupacional está diretamente relacionado ao trabalho. Com base nos conceitos obtidos, também instigamos nossos pesquisados a responderem se a atividade profissional desenvolvida por eles era percebida como estressante. As respostas proferidas revelaram a necessidade de se organizar os discursos em três subcategorias, que denominamos: Sim, Não e em Alguns momentos.

Entendemos a subcategoria Sim, quando o profissional, a partir da sua visão idiossincrática, contempla a atividade bibliotecária como estressante. A subcategoria Não, como aquela que nega a atividade biblioteconômica como causadora de estresse e, por fim, a subcategoria em Alguns momentos, como aquela em que o estresse ocupacional é visto como algo momentâneo. A subcategoria Sim é contemplada por 
uma minoria de nossos pesquisados, entre os quais apenas um dos profissionais analisados afirmou que a profissão bibliotecária é estressante, como será descrito a seguir mediante a transcrição de sua resposta:

Sim, porque a profissão bibliotecária requer que o profissional ocupe uma posição de líder, e como administrador deve tomar decisões, delegar funções, comandar e controlar um grupo de pessoas. O que exige do profissional bastante equilíbrio para lidar com as várias opiniões divergentes. (bibliotecário 1).

Para o bibliotecário 1, o estresse na profissão advém do fato de as pessoas acreditarem que o profissional deva ocupar "uma posição de líder, e como administrador deve tomar decisões, delegar funções, comandar e controlar um grupo de pessoas. O que exige do profissional bastante equilíbrio para lidar com as várias opiniões divergentes".

Podemos inferir que, para o bibliotecário 1, o estresse na profissão está associado a competências profissionais ligadas aos processos de tomadas de decisões e aspectos relacionados à gestão de pessoas.

Com relação à subcategoria Não, tivemos a maioria das respostas, que serão detalhadas a seguir:

Não, às vezes é cansativo, mas não acho uma profissão estressante. Acho uma profissão que não requer muito esforço mental, apesar de requerer organização. (bibliotecário 2)

Não, sendo desenvolvida como atividade vocacional e tendo planejamento e controle das ações, torna-se prazerosa e gratificante pelos resultados atingidos. (bibliotecário 3)

De forma alguma. Pois acredito que não haja profissão estressante e que o que existe de fato são ambientes não propícios, relações não tão saudáveis ou sobrecarrega de atividades no seu local de trabalho que pode causar estresse. (bibliotecário 4)

Na visão do bibliotecário 2, às vezes é cansativa, mas não acha uma profissão estressante. Este a considera uma "profissão que não requer muito esforço mental, apesar de requerer organização". Para o bibliotecário 3, "sendo desenvolvida como uma atividade vocacional e tendo planejamento e controle das ações, [a profissão] torna-se prazerosa e gratificante pelos resultados atingidos”. O bibliotecário 4 [acredita] "que não haja profissão estressante e que o que existe de fato são ambientes não propícios, relações não tão saudáveis ou sobrecarrega de atividades no seu local de trabalho que pode causar estresse".

Infere-se dos discursos apresentados nesta subcategoria, que a profissão não é percebida como estressante. Na fala do bibliotecário 3, é apresentada a questão vocacional como inibidor do estresse na profissão. Chamamos a atenção que nenhuma profissão pode ser exercida pela questão vocacional, sendo esta entendida como predestinação, o que não podemos inferir do discurso do entrevistado, mas esclarecemos que existe uma aptidão para tal, bem como habilidades e competências que são desenvolvidas no decorrer da graduação e do exercício profissional. Crer em vocação com o sentido anteriormente citado é apegar-se a ensinamentos espirituais; entretanto, ao estabelecermos uma relação entre uma profissão com vocação, devemos levar em consideração a liberdade individual de escolha.

Existe sim uma correlação clara entre vocação e escolha de uma profissão, desde que ela seja entendida como aptidão e habilidades inerentes ao indivíduo ou desenvolvida pelo mesmo. Desse modo, a vocação no sentido de Sousa ${ }^{20}$ não se configura como um aspecto que justifique o desencadeamento de estresse ocupacional em uma profissão. O entrevistado chama ainda a atenção para a questão do "planejamento e controle das ações" desenvolvidas para justificar o não desencadeamento do estresse ocupacional na profissão.

Segundo seu discurso, pudemos inferir que o domínio sobre ações de controle e planejamento no exercício da profissão, para ele, é em parte responsável pela ausência de estresse ocupacional na profissão. Isso nos remete ao que Stacciarini e Tróccoli ${ }^{11}$ denominam elementos atenuantes. Segundo eles, esse aspecto sugere questões que amenizam as dificuldades. 
Na visão do bibliotecário 4, não existe profissão estressante; o que torna uma profissão estressante são as condições em que os profissionais as desenvolvem, aspectos esses que se assemelham à visão de Campos $^{15}$, que afirma que um ambiente de trabalho com ausência de condições adequadas pode desencadear problemas físicos e distúrbios mentais no trabalhador.

Deixamos para o final a análise do bibliotecário 2, por apresentar divergência em seu discurso sobre o estresse ocupacional. Na sua concepção, a ausência de estresse ocupacional na sua profissão está associada ao fato de não requerer do profissional esforço mental, embora exija habilidade de organização. Ao discursar desta forma, inferimos uma contradição, que nos permite acreditar que a competência que concerne à atribuição ligada à organização exige deste profissional esforço mental.

Não podemos afirmar, ao certo, que haja desencadeamento de estresse ocupacional no referido bibliotecário pois, para isso, necessitaríamos de um estudo mais aprofundado e a ajuda de profissionais especializados como psicólogos e médicos para o fechamento do diagnóstico. Entretanto, podemos supor, na medida em que ele evidencia cansaço como um aspecto da profissão, que o mesmo pode estar vivenciando situações de estresse ocupacional em seu espaço laboral, embora momentâneo, como podemos evidenciar em seu discurso "às vezes é cansativo, mas não acho uma profissão estressante". O aspecto demonstrado no discurso pode ser observado na literatura adotada na pesquisa como um traço do fenômeno em questão, como afirmam Stacciarini e Tróccoli ${ }^{11}$ assim como Pinheiro e Gunther ${ }^{17}$, entre outros.

Por fim, a terceira e última subcategoria denominada Alguns momentos, que é contemplada por uma pequena parte dos sujeitos analisados, como se observano discurso que segue:

Em alguns momentos sim, pois lidamos cotidianamente com pessoas (usuários, colaboradores) e suas ansiedades e necessidades informacionais, por outro lado dependemos de recursos escassos, problemas estruturais, frustrações em projetos que consideramos essenciais para o bom andamento de unidade em que trabalhamos e que esbarram às vezes na falta de vontade de outros. (bibliotecário 5)

Na visão do bibliotecário 5, em alguns momentos a profissão é vista como estressante, pois se lida cotidianamente "com pessoas (usuários, colaboradores) e suas ansiedades e necessidades informacionais". Por outro lado, dependem de "recursos escassos, problemas estruturais, frustrações em projetos" que são considerados "essenciais para o bom andamento de unidade" em que se trabalha "e que esbarram às vezes na falta de vontade de outros".

A partir do discurso do bibliotecário 5, infere-se que somente em alguns momentos a profissão é tida como estressante, o que se configura como algo pontual. Em seu discurso, colocamos em pauta dois aspectos bastante interessantes que a nosso ver são entendidos como os possíveis fatores de estresse.

Ao mencionar "lidamos cotidianamente com pessoas (usuários, colaboradores) e suas ansiedades e necessidades informacionais", colocamos em pauta a questão das relações interpessoais e até que ponto elas podem interferir nessa questão do estresse ocupacional. Esse aspecto das relações interpessoais é fundamentado nos estudos de Stacciarini e Tróccoli ${ }^{11}$ que, segundo eles, são apreendidas como categoria de elementos estressores.

Ainda na mesma colocação, acredita-se que o pesquisado não esteja se referindo a uma mesma pessoa ou a um grupo de pessoas específico, e sim à comunidade que o centro informacional atende, o que dá uma denotação de que cada usuário ou colaborador tenha uma necessidade momentânea.

Outro aspecto evidenciado pelo respondente é a questão da dependência “de recursos escassos, problemas estruturais, frustrações em projetos que consideramos essenciais para o bom andamento de unidade em que trabalhamos e que esbarram às vezes na falta de vontade de outros". Esse aspecto remete ao que os autores anteriormente citados discorrem sobre poder de decisão, que é visto como a "limitação em que o profissional em seu espaço laboral é submetido por depender de instâncias superiores para a solução de problemas"11. 
Uma vez explicitada a concepção de estresse ocupacional dos pesquisados e evidenciado, através de suas respostas, que a atividade desenvolvida por eles é estressante, no tópico seguinte demonstraremos, segundo suas respostas, as principais fontes de estresse na instituição analisada.

\section{Fatores geradores de estresse na atividade bibliotecária na Universidade Estadual do Piauí}

No intuito de verificar a existência de fatores desencadeadores de estresse no espaço laboral da Universidade Estadual do Piauí (Uespi), partimos do seguinte questionamento aos nossos respondentes: que fatores você evidencia como fonte geradora de estresse na profissão bibliotecária desenvolvida por você na Uespi?

No tocante a esse questionamento, os bibliotecários em exercício que participaram da pesquisa evidenciaram vários fatores desencadeadores de estresse. Em nossa análise, esses fatores foram agrupados por ordem de proximidade e organizados em três subcategorias denominadas: fatores intrínsecos ao trabalho, poder de decisão e carga de trabalho. A primeira subcategoria está fundamentada nas ideias de Cooperix* e as demais nas ideias de Stacciarini e Tróccoli1"

Cooperx* classifica os prováveis fatores geradores de estresse no trabalho de acordo com vários enfoques. Entretanto, em nosso estudo, apenas um se enquadra na perspectiva das respostas dos sujeitos pesquisados, assim como apenas dois de Stacciarini e Tróccoli ${ }^{11}$ são observados nos discursos dos respondentes.

Cooperxi* define fatores intrínsecos ao trabalho como os recursos inadequados, ou seja, as dificuldades provenientes das condições materiais e humanas visualizadas como inapropriadas para o desenvolvimento da atividade profissional.

Já Stacciarini e Tróccoli11 definem o poder de decisão como a limitação da autoridade do profissional para solucionar uma série de problemas, ficando sempre a depender de instâncias superiores e, por fim, a carga de trabalho é definida por ambos como o tempo dispensado para a realização de tarefas, cuja quantificação é também realizada.

Uma vez explicado em que consiste cada subcategoria, evidenciaremos, a seguir, no Quadro 1 com as respostas fornecidas pelos bibliotecários, organizadas em suas respectivas subcategorias, o número de vezes que cada resposta se repete.

Quadro 1 - Fatores geradores de estresse ocupacional nos bibliotecários da Universidade Estadual do Piauí- Uespi

\begin{tabular}{|c|c|c|c|c|c|}
\hline $\begin{array}{l}\text { Fatores } \\
\text { intrínsecos ao } \\
\text { trabalho } \\
\end{array}$ & $\begin{array}{l}\text { No de } \\
\text { vezes }\end{array}$ & Poder de decisão & $\begin{array}{l}\text { No de } \\
\text { vezes }\end{array}$ & $\begin{array}{l}\text { Carga de } \\
\text { trabalho }\end{array}$ & $\begin{array}{l}\text { No de } \\
\text { vezes }\end{array}$ \\
\hline $\begin{array}{l}\text { O fato de lidar com } \\
\text { trabalho manual } \\
\text { pesado }\end{array}$ & 1 & $\begin{array}{l}\text { As dificuldades } \\
\text { que a instituição e, } \\
\text { consequentemente, } \\
\text { sua biblioteca estão } \\
\text { enfrentando no momento }\end{array}$ & 1 & $\begin{array}{l}\text { O excesso de } \\
\text { atividades frente à } \\
\text { grande demanda } \\
\text { existente }\end{array}$ & 1 \\
\hline $\begin{array}{l}\text { Falta de recursos } \\
\text { materiais e de } \\
\text { pessoal }\end{array}$ & 2 & $\begin{array}{l}\text { Precariedade de recursos } \\
\text { financeiros }\end{array}$ & 1 & & \\
\hline $\begin{array}{l}\text { Falta de software } \\
\text { para a automação da } \\
\text { biblioteca }\end{array}$ & 1 & $\begin{array}{l}\text { Descaso por parte dos } \\
\text { gestores em relação às } \\
\text { atividades bibliotecárias }\end{array}$ & 1 & & \\
\hline $\begin{array}{l}\text { Espaço físico } \\
\text { deficiente }\end{array}$ & 1 & & & & \\
\hline
\end{tabular}

ix ${ }^{*} 1993$, apud $^{11}$

$x$ * 1993, apud $^{11}$

xi ${ }^{*} 1993$, apud $^{11}$ 


\begin{tabular}{|c|c|c|c|c|c|}
\hline $\begin{array}{l}\text { Fatores } \\
\text { intrínsecos ao } \\
\text { trabalho }\end{array}$ & $\begin{array}{l}\text { No de } \\
\text { vezes }\end{array}$ & Poder de decisão & $\begin{array}{l}\text { No de } \\
\text { vezes }\end{array}$ & $\begin{array}{l}\text { Carga de } \\
\text { trabalho }\end{array}$ & $\begin{array}{l}\text { No de } \\
\text { vezes }\end{array}$ \\
\hline $\begin{array}{l}\text { Falta de } \\
\text { computadores para } \\
\text { atendimento }\end{array}$ & 1 & & & & \\
\hline Total & 6 & & 3 & & 1 \\
\hline
\end{tabular}

Fonte: Elaboração própria com base nos dados obtidos com a pesquisa.

Como demonstrado no Quadro 1, foram evidenciados nove fatores como fontes geradoras de estresse ocupacional na atividade desenvolvida pelos bibliotecários no espaço laboral da Universidade Estadual do Piauí. Nesse total, encontram-se subcategorias, como podemos observar a seguir. Desse modo, temos, inicialmente, fatores intrínsecos ao trabalho, que na perspectiva dos discursos são:

Precariedade de recursos [...] material e de pessoal. (bibliotecário 1)

O fato de lidar com trabalho manual pesado. (bibliotecário 2)

Falta de pessoal acaba por tornar a rotina dinâmica, levando por vezes à perda de foco. (bibliotecário 3)

Em termos técnicos eu diria que a falta de estrutura básica e de mecanismos essenciais (software para a automação da biblioteca, espaço físico deficiente, computadores para atendimento) são alguns deles. (bibliotecário 5)

Para o bibliotecário 1, as fontes de estresse na ocupação de bibliotecário na Universidade Estadual estão diretamente ligadas à precariedade de recursos materiais e pessoais. Embora não esteja explícito em seu discurso o que significa a precariedade de recurso pessoal, inferimos a partir de nossas observações que seja a ausência de uma quantidade de profissionais qualificados para o exercício das atividades inerentes à profissão da área de biblioteconomia. O mesmo discurso se repete na resposta do bibliotecário 3, ao dizer que a "falta de pessoal acaba por tornar a rotina dinâmica, levando por vezes à perda de foco". Podemos inferir do discurso do bibliotecário 3 que a rotina das atividades desenvolvidas no espaço laboral do bibliotecário na Uespi é comprometida pela variedade de atividades que, segundo ele, leva à perda de foco, e consequentemente, à minimização do término das tarefas.

Para o bibliotecário 2, o estresse é associado ao "fato de se lidar com trabalho manual pesado". Não podemos inferir a quais atividades o respondente está se referindo; entretanto, no momento da explicação do questionário ao respondente em seu espaço laboral, pudemos observar a utilização de fichas manuais bem como a ausência de qualquer estrutura e recursos que pudessem maximizar a eficácia e a eficiência no trabalho desenvolvido pelo mesmo, o que converge para o que o bibliotecário 5 afirma serem os motivos geradores de estresse: "em termos técnicos [...] a falta de estrutura básica e de mecanismos essenciais (software para a automação da biblioteca, espaço físico deficiente, computadores para atendimento).

A segunda subcategoria denominada poder de decisão é contemplada com três aspectos geradores de estresse, relatados a seguir:

As dificuldades que a instituição e consequentemente a biblioteca estão enfrentando no momento, [...] Precariedade de recursos financeiros. (bibliotecário 1) 
Essa subcategoria está diretamente ligada à falta de autonomia do profissional e à sua subordinação a órgãos ou instâncias superiores. Na visão do bibliotecário 1, "as dificuldades que a instituição e consequentemente a biblioteca estão enfrentando no momento", assim como a "precariedade de recursos financeiros" são apontados como fontes geradoras de estresse. Para o bibliotecário 4, o estresse é advindo do "descaso por parte dos gestores em relação às atividades bibliotecárias".

Podemos inferir do discurso do bibliotecário 1 que, se a instituição Uespi como um todo passa por dificuldades, consequentemente todas as instâncias ligadas a ela também passarão, inclusive a biblioteca. Ainda é apontado pelo bibliotecário 1, o fator "precariedade de recursos financeiros". As dificuldades enfrentadas pela universidade refletem consequentemente no espaço laboral das bibliotecas, evidenciando problemas para seus profissionais que são apontadas por nossos respondentes como: falta de estrutura básica para o desenvolvimento das atividades dos profissionais, falta de mão de obra qualificada, entre outros aspectos. A presença desses aspectos podem comprometer a efetivação das atividades do bibliotecário e, também, desenvolver, nos profissionais envoltos nessas condições, estresse ocupacional.

Já do discurso do bibliotecário 4 podemos inferir que o estresse está ligado à negação da importância do profissional bibliotecário na sociedade piauiense, assim como no âmbito da universidade em questão por parte de gestores. Tal afirmação é respaldada pelo fato de a profissão ainda não estar no quadro de profissões do estado do Piauí.

Essa informação não está implícita no discurso de nosso respondente. Entretanto, ela se faz necessária pelo fato de a universidade em questão ser de âmbito estadual, necessitar do profissional em questão no seu quadro de profissões efetivas e não poder efetivá-lo. Verifica-se que o espaço da profissão na universidade em questão, bem como em qualquer outro órgão público estadual, é restrito a contratos com prazos determinados, o que ocasiona um grande fluxo de rotatividade dos profissionais. Em suma, o fato de a profissão não ser ainda legalizada no estado do Piauí compromete o desenvolvimento das atividades nesses espaços.

A terceira subcategoria, denominada carga de trabalho conta com a minoria das respostas, contemplando apenas um aspecto como fonte geradora de estresse ocupacional nos bibliotecários em exercício da Universidade Estadual do Piauí.

O excesso de atividades frente à grande demanda existente. (bibliotecário 3)

Para o bibliotecário 3, "o excesso de atividades frente à grande demanda existente” é considerado como uma fonte geradora de estresse ocupacional na atividade bibliotecária. Podemos inferir que este aspecto é resultado da discussão anterior, reflexo do que o bibliotecário 1 mencionou como "dificuldades que a instituição e consequentemente a biblioteca estão enfrentando no momento”.

Infere-se ainda que, com a presença de um número reduzido de profissionais qualificados na área de biblioteconomia, o desenvolvimento das atividades inerentes à profissão seja executado com excesso de trabalho para cada profissional em exercício, pois cada biblioteca analisada da universidade conta com, no máximo, dois bibliotecários em cada campus universitário. A seguir, discutiremos a categoria que analisa as implicações dos estressores tanto para a instituição como para os profissionais a ela vinculados.

\section{Implicações dos estressores para a instituição Uespi e para os profissionais bibliotecários}

Para elucidar essa categoria, partimos do seguinte questionamento: quais as implicações dos estressores (se houver) para as bibliotecas da Uespi e para o desempenho profissional do bibliotecário? A partir dos discursos de nossos respondentes, várias foram as implicações elencadas por eles. Com base no exposto em seus discursos, agrupamos as respostas em duas subcategorias: conciliar as atividades exigidas pelo cotidiano do trabalho e nível de satisfação dos indivíduos. 
Essas duas subcategorias serão evidenciadas através do Quadro 2, em que será apresentado o número de vezes que cada resposta se repetiu, possibilitando o cálculo do percentual que cada subcategoria representa, e no qual as implicações são agrupadas segundo o grau de proximidade.

Quadro 2 - Implicações dos estressores para Uespi e bibliotecários

\begin{tabular}{|c|c|c|c|}
\hline $\begin{array}{l}1^{\text {a }} \text { Categoria - Conciliar as } \\
\text { atividades exigidas pelo cotidiano } \\
\text { do trabalho }\end{array}$ & $\begin{array}{l}\mathrm{N}^{\circ} \mathrm{de} \\
\text { vezes }\end{array}$ & $\begin{array}{l}2^{\text {a }} \text { Categoria - Nível de } \\
\text { satisfação dos indivíduos }\end{array}$ & $\begin{array}{l}\mathrm{N}^{\circ} \mathrm{de} \\
\text { vezes }\end{array}$ \\
\hline $\begin{array}{l}\text { Interferem no adequado } \\
\text { desenvolvimento das atividades }\end{array}$ & 1 & Rendimento profissional & 1 \\
\hline Morosidade no atendimento ao usuário & 1 & Frustração & 1 \\
\hline Eficiència das bibliotecas e serviços & 1 & & \\
\hline Total & 3 & & 2 \\
\hline
\end{tabular}

Fonte: Elaboração própria com base nos dados obtidos com a pesquisa.

A primeira subcategoria está diretamente ligada às implicações para as instituições estudadas, ou seja, as implicações para as bibliotecas vinculadas à Universidade Estadual do Piauí. As mesmas estão fundamentadas nos estudos de Fernandes, Medeiros e Ribeiro ${ }^{14}$, em que eles conceituam conciliar as atividades exigidas pelo cotidiano como as dificuldades de corresponder às demandas impostas pelo cotidiano do trabalho. A primeira subcategoria nos remete às seguintes falas:

Acho que direta ou indiretamente acabam interferindo no adequado desenvolvimento das atividades, pois o indivíduo quando se depara com uma situação estressante perde um pouco do seu rendimento (sua capacidade de produção). (bibliotecário 1)

Morosidade no atendimento ao usuário [...]. (bibliotecário 3)

A biblioteca deixa de exercer seu papel com a eficiência devida, não disponibilizando o acesso a informações em diversos suportes, deixando a desejar em suas estruturas, no conforto e na locomoção de seus usuários. (bibliotecário 5)

Para o bibliotecário 1, as implicações "direta ou indiretamente acabam interferindo no adequado desenvolvimento das atividades”. Já para o bibliotecário 3, as implicações dos estressores associam-se à lentidão no atendimento ao usuário.

Para o bibliotecário 5, as implicações incidem sobre o papel da biblioteca, que para ele "deixa de exercer seu papel com a eficiência devida, não disponibilizando o acesso a informações em diversos suportes, deixando a desejar em suas estruturas, no conforto e na locomoção de seus usuários".

Podemos inferir que, para esses três bibliotecários, as implicações giram em torno do cumprimento do papel do centro informacional, do desenvolvimento das atividades, bem como do tempo para a execução das mesmas. O bibliotecário 5 amplia essas implicações, evidenciando aspectos como: estrutura, conforto e locomoção dos usuários. Fernandes, Medeiros e Ribeiro ${ }^{14}$ pontuam ainda sobre essa questão da conciliação das atividades no espaço laboral afirmando que:

[...] o ritmo acelerado e a sobrecarga se destacam e, ao mesmo tempo, conciliar essas exigências com as dimensões do mundo privado, tais como a convivência familiar e as demandas subjetivas do exercício da individualidade, constituem-se como uma queixa e um sinal emblemático da complexidade do cotidiano. 
Os autores colocam em pauta mais um fator importante, que é a questão subjetiva de cada pessoa, no caso do estudo, o trabalhador, ou seja, o que cada um traz para seu espaço de trabalho pode contribuir ou não para o estresse.

Com relação à segunda subcategoria, que está ligada exclusivamente às implicações para os profissionais bibliotecários, obtivemos as seguintes respostas:

[...] o indivíduo, quando se depara com uma situação estressante, perde um pouco do seu rendimento (sua capacidade de produção) [...] (bibliotecário 1)

[...] frustração por não poder prestar melhores serviços. (bibliotecário 5)

Na visão do bibliotecário 1, "o indivíduo, quando se depara com uma situação estressante, perde um pouco do seu rendimento (sua capacidade de produção)". Para o bibliotecário 5, as implicações do estresse ocupacional dão-se na forma de "frustração por não poder prestar melhores serviços".

Podemos inferir que a consequência dos estressores para o bibliotecário 1 recai sobre seu rendimento profissional. A literatura diz que, na maioria das vezes, as consequências do estresse ocupacional se dão na forma de cansaço físico, irritabilidade, ou seja, características relacionadas a aspectos fisiológicos ou orgânicos, como demonstram os estudos de Fernandes, Medeiros e Ribeiro ${ }^{14}$, quando afirmam que as consequências do estresse no trabalho se dão na forma de:

[...] incapacidade de lidar com as fontes de pressão no trabalho, provocando consequências sob a forma de problemas na saúde física e mental e na satisfação no trabalho, comprometendo os indivíduos e as organizações.

Os estudos de Bicho e Pereira ${ }^{13}$ também afirmam que as consequências do estresse ocupacional, em nível individual, se dão principalmente em termos da saúde mental e física. Os autores ainda mencionam que as consequências do estresse para as organizações e/ou instituições provêm das individuais, uma vez que as instituições são compostas por pessoas.

Como vimos no discurso do bibliotecário 5 , as implicações para ele enquanto profissional se dão na forma de frustração, ou seja, manifestando uma emoção, que é percebida quando ele menciona "frustração por não poder prestar melhores serviços", situação que o impede de alcançar seus objetivos profissionais. Inferirmos que estes sejam proporcionar a seus usuários, de forma eficaz e eficiente, os serviços que competem à sua profissão.

Embora a afirmação do bibliotecário 5 esteja em divergência com as consequências em âmbito individual sobre a forma da saúde mental e física que os autores vêm discutindo, o seu discurso encontra base nos estudos de Fernandes, Medeiros e Ribeiro ${ }^{14}$ e vai ao encontro do que eles chamam de insatisfação no trabalho.

Cabe esclarecer que a ausência de respostas dos bibliotecários 2 e 4 se dá porque o respondente 2 afirma em seu discurso que as implicações do estresse não atrapalham no desenvolvimento de suas atividades e o respondente 4 não respondeu a essa questão. Dessa forma, não possuímos elementos representativos para analisá-los, uma vez que a técnica de análise de conteúdo necessita o mínimo possível de conteúdo para que sejam cumpridas suas etapas: organização dos dados, descrição dos discursos, inferências e, por fim, a análise interpretativa ${ }^{9}$.

\section{Considerações finais}

A temática do estresse ocupacional, como já falamos, não é atual. Entretanto, continua a ser uma preocupação mundial. Acreditamos que o estudo proposto nos possibilita uma reflexão sobre as fontes geradoras de estresse nos profissionais bibliotecários da Universidade Estadual do Piaú e da classe 
profissional em questão de modo a compreendê-las. Permite, ainda, revelar sentimentos e motivações de nossos analisados enquanto profissionais que desempenham um papel de grande relevância para a sociedade.

Não podemos, aqui, fechar um diagnóstico certo da ocorrência de estresse ocupacional no espaço laboral analisado. Entretanto, podemos evidenciar, a partir dos discursos de nossos respondentes, os sentidos produzidos pelos mesmos acerca da temática e apontar fontes geradoras de estresse elencadas no estudo, bem como as consequências desses aspectos para a instituição Uespi e, principalmente, para os profissionais bibliotecários que lá exercem sua atividade profissional.

É demonstrado, pela maioria dos discursos, que a profissão não é percebida como estressante, embora sejam apontadas fontes geradoras de estresse sob três enfoques: fatores intrínsecos ao trabalho, poder de decisão e carga de trabalho.

As implicações dos estressores para a instituição Uespi e para os profissionais bibliotecários estão envoltas em dois aspectos: o primeiro se refere a conciliar as atividades exigidas pelo cotidiano do trabalho e o segundo ao nível de satisfação dos indivíduos.

O primeiro aspecto está diretamente ligado às implicações para a instituição Uespi e se encontra na maioria dos discursos: as implicações segundo nossos respondentes se apresentam sob a seguinte forma: desenvolvimento inadequado das atividades bibliotecárias, morosidade no atendimento ao usuário, ineficiências das bibliotecas e serviços, ou seja, os centros informacionais analisados deixam de exercer seu papel diante da comunidade. O segundo aspecto tem implicações diretamente sobre nossos respondentes, e se apresenta na forma de baixo rendimento profissional e frustração.

Como contribuição do estudo, pontuamos sugestões para a minimização dos efeitos das fontes elencadas de estresse no espaço laboral analisado. Trata-se de atividades direcionadas aos nossos pesquisados em âmbito individual e em nível organizacional para a Instituição Uespi.

Com relação ao aspecto individual, apresentamos como sugestão:

- Desenvolver atividades físicas cotidianamente;

- Buscar repousar, lazer e diversão (organização do tempo livre com atividades prazerosas e atrativas), além de manter atividades sociais;

- $\quad$ Entender que cada ser humano possui sua subjetividade; logo, é natural que os mesmos pensem e sintam de maneira bem singular, cada um de sua forma. E que as divergências, muitas vezes, impulsionam grandes modificações e que, a partir disso, podemos nos reavaliar para desenvolvermos habilidades.

Com relação ao nível organizacional para a instituição Uespi, temos:

- Contratação imediata, através de concurso, de profissionais especializados com o intuito de minimizar a carga de trabalho para cada bibliotecário;

- Desenvolver programas interdisciplinares de apoio e prevenção do estresse, principalmente com professores dos cursos da Facime das áreas de medicina e psicologia bem como com professores da área de educação física a fim de melhorar a qualidade de vida de seus trabalhadores;

- Realização de ginástica laboral antes de um dia de trabalho com o objetivo de aumentar o potencial físico e psicológico do trabalhador;

- Contratação de medidas ergonômicas: o profissional bibliotecário pode ser orientado por um profissional especializado (ergonomista) a tomar certos cuidados ao sentar, ao levantar pesos, ao transportar materiais (no caso, usar um carrinho adequado), com a altura dos móveis, principalmente no balcão de atendimento ao usuário. 
O desenvolvimento de estratégias como essas torna a vida desses trabalhadores mais saudável e possibilita aumentar a frequência e a intensidade de estados emocionais positivos, como tranquilidade e bem-estar.

Nosso estudo finda, no mesmo ponto em que se iniciou, com o olhar para o contexto laboral em que se realiza a atividade bibliotecária. Tendo a esperança de que outras pesquisas despertem o interesse pela temática em questão.

\section{Referências}

1. $\quad$ Rodrigues JA. O mal-estar docente: trabalho, saúde e educação [dissertação]. Joaçaba (SC): Universidade do Oeste de Santa Catarina, Mestrado em Educação; 2009.

2. $\quad$ Lipp MN. O stress do professor. Campinas: Papirus; 2002.

3. Molina OF. Estresse no cotidiano. Santa Cecilia: Pancast; 1999.

4. Menezes J F de. Qualidade de vida no trabalho e stress ocupacional. São Paulo: Libertas; 2006.

5. Inocente NJ. Síndrome de Burnout em professores universitários do Vale do Paraíba [Tese]. Campinas (SP): Universidade de Campinas, Doutorado em Ciências Médicas; 2005.

6. Tamayo RM. Relação entre a Síndrome do Burnout e os valores organizacionais no pessoal de enfermagem de dois Hospitais Públicos [dissertação]. Brasília: Universidade de Brasília, Brasília, Mestrado em Psicologia; 1997.

7. França A C. L, Rodrigues A L. Stress e Trabalho: uma abordagem psicossomática. 3a ed. São Paulo: Atlas; 2002.

8. Seyle H. Stress: a tensão da vida. 2a ed. São Paulo: Ibrasa; 1965.

9. Bardin L. Análise de conteúdo. Lisboa: Edições; 2002.

10. Childre DL. A gestão do stress: freeze frame: uma técnica para o alívio do stress no momento. Lisboa: Dinalivro; 1997.

11. Stacciarini JMR, Tróccoli BT. O estresse na atividade ocupacional do enfermeiro. Revista LatinoAmericana de Enfermagem. 2001; 9 (2): 17-25.

12. Sparrebenger F, Santos I, Lima R. Epidemiologia do distress psicológico: estudo transversal de base populacional. Rev. Saúde Pública. 2003; 37 (4): 434-439.

13. Bicho LMD, Pereira S R. Estresse Ocupacional [internet]. Coimbra: Instituto Politécnico de Coimbra. 2007 - [citado 10 set. 2007] . Disponível em: http://docs.google.com/viewer?a=v\&q=cache:MG6Gi3FXWC MJ:prof.santana-e-silva.pt/gestao de empresas/trabalhos 06 07/word/Stress\%25200cupacional. pdf+Estresse+Ocupacional.

14. Fernandes SBM.A, Medeiros SM, Ribeiro L M. Estresse ocupacional e o mundo do trabalho atual: repercussões na vida cotidiana das enfermeiras. Revista Eletrônica de Enfermagem. 2008; 10 (2): 414427.

15. Campos EF. Estresse e ler/dort no trabalho. [Trabalho de Conclusão de Curso]. Goiás: Universidade Estadual de Goiás, Graduação em Administração; 2009.

16. Chiavenato I. Gestão de Pessoas. 3a ed. Rio de Janeiro: Campus; 2009.

17. Pinheiro FA, Gunther I. A. Estresse Ocupacional e indicadores de saúde em gerentes de um banco estatal. Revista Psicologia: organização e trabalho, Florianópolis. 2002; 2 (2): 65-84.

18. Smith KK, Kaminstein DS, Makadok RJ. The health of the corporate body: ilness and organizational dynamics. Journal of applied behavioral science. 1995; 31 (3): 328-351.

19. Lourenço M L, Almeida, T. Estresse Ocupacional e Assédio Moral Em Profissionais Bibliotecários. 2009 [internet]. Disponível a partir de em: http://www.artigonal.com/psicologiaauto-ajuda-artigos/ estresse-ocupacional-e-assedio-moral-em-profissionais-bibliotecarios-735925.html.

20. Sousa LG. Ética e Sociedade. Espanha: Eumed; 2006. 